\title{
Changes in the expression of NO synthase isoforms after ozone: the effects of allergen exposure
}

\author{
An-Soo Jang*1, Inseon-S Choi ${ }^{2}$, Jong-Un Lee ${ }^{3}$, Sung-Woo Park ${ }^{1}$, June- \\ Hyuk Lee ${ }^{1}$ and Choon-Sik Park ${ }^{1}$
}

\begin{abstract}
Address: ${ }^{1}$ Department of Internal Medicine, Soonchunhyang University Hospital, Bucheon, 1174, Jung-dong, Wonmi-gu, Bucheon-si, Gyeonggido, 420-767 Republic of Korea, ${ }^{2}$ Research Institute of Medical Sciences, Department of Internal Medicine, Chonnam National University, 8, Hak1-dong, Gwangju, 501-757, Republic of Korea and 3Physiology, Chonnam National University Medical School, Chonnam National University, 5, Hak-1-dong, Gwangju, 501-757, Republic of Korea

Email: An-Soo Jang* - jas877@schbc.ac.kr; Inseon-S Choi - ischoi@chonnam.chonnam.ac.kr; Jong-Un Lee - julee@jnu.ac.kr; SungWoo Park - swpark@schbc.ac.kr; June-Hyuk Lee - junehyuk@schbc.ac.kr; Choon-Sik Park - mdcspark@unitel.co.kr

* Corresponding author
\end{abstract}

Published: 05 June 2004

Respiratory Research 2004, 5:5

This article is available from: http://respiratory-research.com/content/5/I/5

(C) 2004 Jang et al; licensee BioMed Central Ltd. This is an Open Access article: verbatim copying and redistribution of this article are permitted in all media for any purpose, provided this notice is preserved along with the article's original URL.

\begin{abstract}
Background: The functional role of nitric oxide (NO) and various nitric oxide synthase (NOS) isoforms in asthma remains unclear.

Objective: This study investigated the effects of ozone and ovalbumin (OVA) exposure on NOS isoforms.

Methods: The expression of inducible NOS (iNOS), neuronal NOS (nNOS), and endothelial NOS (eNOS) in lung tissue was measured. Enhanced pause $\left(P_{\text {enh }}\right)$ was measured as a marker of airway obstruction. Nitrate and nitrite in bronchoalveolar lavage (BAL) fluid were measured using a modified Griess reaction.

Results: The nitrate concentration in BAL fluid from the OVA-sensitized/ozone-exposed/OVAchallenged group was greater than that of the OVA-sensitized/saline-challenged group. Methacholine-induced $P_{\text {enh }}$ was increased in the OVA-sensitized/ozone-exposed/OVA-challenged group, with a shift in the dose-response curve to the left, compared with the OVA-sensitized/ saline-challenged group. The levels of nNOS and eNOS were increased significantly in the OVAsensitized/ozone-exposed/OVA-challenged group and the iNOS levels were reduced compared with the OVA-sensitized/saline-challenged group.
\end{abstract}

Conclusion: In mice, ozone is associated with increases in lung eNOS and nNOS, and decreases in iNOS. None of these enzymes are further affected by allergens, suggesting that the NOS isoforms play different roles in airway inflammation after ozone exposure.

\section{Introduction}

Asthma is an inflammatory disease of the airways that is characterized by airway obstruction and increased airway responsiveness [1]. NO (nitric oxide) is a short-lived 
molecule that causes vasodilation and bronchodilation. It is synthesized from L-arginine by three forms of the enzyme NO synthase: two constitutive NO synthases (cNOS) are involved in the physiological regulation of airway function, and an inducible form of the enzyme (iNOS) is involved in inflammatory disease of the airways and in host defense against infection $[2,3]$.

We previously demonstrated that NO metabolites were increased in tracheo-bronchial secretions of asthmatic subjects in parallel with asthma severity, and that NO metabolites in sputum are a more valuable indicator for monitoring asthmatic airway inflammation than those in serum $[4,5]$.

Ozone is an important component of the photochemical oxidation product of air pollution emitted from automobile engines [6]. Acute ozone exposure decreases pulmonary function, increases airway hyper-responsiveness (AHR), and induces airway inflammation in dogs [7], guinea pigs [8], and humans [9-11]. NO may play a critical role in ozone-induced pulmonary inflammation or damage. We reported that the nNOS isoform might be involved in airway obstruction in mice exposed to ozone [12]. The functional roles of neuronal NOS (nNOS), endothelial NOS (eNOS), and iNOS in the murine model of asthma with ozone exposure are uncertain.

This study investigated the roles of the individual NOS isoforms and evaluated the relationship between NO metabolites and lung function using barometric wholebody plethysmography (WBP) in mice after ozone and allergen exposure.

\section{Methods \\ Mice}

Female BALB/c mice (DaeMul Laboratories, Daejeon, Korea) known to IgE-high responder, aged 5 to $6 \mathrm{wk}$, were used. The mice were maintained on ovalbumin free diets. The mice were individually housed in rack-mounted stainless steel cages with free access to food and water.

\section{Ovalbumin-induced allergic airway disease model}

An ovalbumin (OVA)-induced allergic airway disease model of asthma with some modification was used [13]. Briefly, mice were sensitized by means of intra-peritoneal injection of on day $1,14 \mathrm{~d}$ with $10 \mu \mathrm{g}$ of Grade V OVA (Sigma Chemical, St Louis, Mo) and $1 \mathrm{mg}$ of aluminum potassium sulfate (Sigma Chemical) in $500 \mu \mathrm{L}$ of saline solution. Mice were then challenged on days 21 to 23 by daily exposure (30 $\mathrm{min})$ to an aerosol of $1 \%(\mathrm{wt} / \mathrm{vol})$ OVA in saline solution. Vehicle control mice were sensitized with a suspension of aluminum potassium sulfate $(1 \mathrm{mg})$ in saline solution $(500 \mu \mathrm{L})$ and challenged with nebulized saline solution daily from days 21 to 23 . Aerosol chal- lenge was carried out on groups of up 20 mice in a closed system chamber attached to an ultrasonic nebulizer (NEUO7; Omron Corporation, Tokyo, Japan) with an output of $1 \mathrm{~mL} / \mathrm{min}$ and 1 - to $5-\mu \mathrm{m}$ particle size.

\section{Ozone exposure}

The mice housed in whole-body exposure chambers were exposed to ozone concentrations of $2 \mathrm{ppm}$ for $3 \mathrm{~h}(\mathrm{n}=6)$, which dose and time of ozone was selected according to our previous study [14]. Ozone was generated with Sander Model 50 ozonizers (Sander, Eltze, Germany). The concentration of ozone within the chambers was monitored throughout the exposure with ambient-air ozone motors (Model 49C; Thermo Environmental Instruments Inc., Franklin, Mass). The air-sampling probes were placed in the breathing zone of the mice. The mean chamber ozone concentration ( \pm SEM) during the $3 \mathrm{hr}$ exposure period was $1.98 \pm 0.06 \mathrm{ppm}$. The breathing parameter values of spontaneously breathing $\mathrm{BALB} / \mathrm{c}$ mice were determined under standard conditions at room air and temperature.

\section{Determination of airway responsiveness}

Airway responsiveness was measured by barometric plethysmography using whole body plethysmography (Buxco, Troy, NY) immediately after ozone exposure while the animals were awake and breathing spontaneously as a modification of the method described by Hamelmann et al [15]. Penh measured in mice using barometric plethysmography is a valid indicator of bronchoconstriction and can be used to measure AHR [15-17]. Bronchoconstriction is known to alter breathing patterns, and changes in Pause (timing of early and late expiration) and Penh are really due to alterations in the timing of breathing, as well as prolongation of the expiratory time. Furthermore, airway constriction increases the thoracic flow asynchronously with the nasal flow, resulting in an increase in the box pressure signal. Penh is an empiric parameter that reflects changes in the waveform of the measured box pressure signal that are a consequence of bronchoconstriction. Before taking readings, the box was calibrated with a rapid injection of $150 \mu \mathrm{l}$ air into the main chamber. Measured were pressure differences between the main chamber of the WBP containing the animal, and a reference chamber (box pressure signal). This box pressure signal is caused by volume and resultant pressure changes in the main chamber during the respiratory cycle of the animal. A pneumotachograph with defined resistance in the wall of the main chamber acts as a low pass filter and allows thermal compensation. The time constant of the box was determined to be approximately $0.02 \mathrm{~s}$. Mice were placed in the main chamber, and baseline readings were taken and averaged for $3 \mathrm{~min}$. 


\section{Bronchoalveolar lavage (BAL) fluid preparation and analysis}

BAL was performed immediately after the last measurement of airway responsiveness. The mice were deeply anesthetized intraperitoneally with $50 \mathrm{mg} / \mathrm{kg}$ of pentobarbital sodium and were killed by exanguination from the abdominal aorta. The trachea was cannulated with a polyethylene tube through which the lungs were lavaged three times with $1.0 \mathrm{ml}$ of physiologic saline $(4.0 \mathrm{ml}$ total). The BAL fluid was filtered through wet $4 \times 4$ gauze. Trypan blue exclusion for viability and total cell count was performed. The BAL fluid was centrifuged at $150 \times \mathrm{g}$ for 10 min. The obtained pellet was immediately suspended in 4 $\mathrm{ml}$ of physiologic saline, and total cell numbers in the BAL fluid were counted in duplicate with hemocytometer (improved Neubauer counting chamber). Then, a $100 \mu \mathrm{l}$ aliquot was centrifuged in a cytocentrifuge (Model 2 Cytospin; Shandon Scientific Co., Pittsburg, PA). Differential cell counts were made from centrifuged preparations stained with Diff-quick, counting 500 or more cells in each animal at a magnification $\times 1,000$ (oil immersion).

\section{OVA-specific IgE}

Serum was obtained by means of orbital bleeding of anesthetized mice on day 25 of the sensitization-challenge protocol, 24 hrs after the final OVA or saline challenge. Serum was stored in $100-\mu \mathrm{L}$ aliquots at $-73^{\circ} \mathrm{C}$ until processed for measurement of OVA-specific IgE. OVA-specific IgE levels were quantitated by using ELISA, as previously described [18]. Briefly, flat-bottomed, 96-well ELISA plates (Immuno Maxisorp; Nalge Nunc International, Roskilde, Denmark) were coated overnight at $4{ }^{\circ} \mathrm{C}$ with $100 \mu \mathrm{g} / \mathrm{mL}$ OVA in coating buffer $\left(\mathrm{NaHCO}_{3}, 1.94 \mathrm{~g} / \mathrm{L}\right.$; $\mathrm{NaCO}_{3}, 3.52 \mathrm{~g} / \mathrm{L}$; and $\mathrm{dH}_{2} \mathrm{O}, 1 \mathrm{~L}$ [pH9.6]). After 3 washes with $0.5 \%$ Tween-20/PBS plates were blocked with 200 $\mu \mathrm{L} /$ well of $1 \% \mathrm{BSA} / \mathrm{PBS}$ for $1.5 \mathrm{hrs}$ at $37^{\circ} \mathrm{C}$. After 6 washes with $0.5 \%$ Tween-20/PBS, serum samples (1:10, 1:50, and 1:100 dilutions in 1\% BSA/PBS) were incubated for 1.5 hrs at $37^{\circ} \mathrm{C}$. Pooled sera from OVA sensitized-challenged mice served as a positive control, and pooled normal mouse sera served as a negative control. After 6 washes with $0.5 \%$ Tween-20/PBS, $100 \mu \mathrm{L} /$ well of sheep antimouse IgE (1:8000 in 1\% BSA/PBS, Calbiochem-Novabiochem Corp, La Jolla, Calif) was added for $1.5 \mathrm{hrs}$ at $37^{\circ} \mathrm{C}$. After 6 washes with $0.5 \%$ Tween-20/PBS, $100 \mu \mathrm{L} /$ well of horseradish peroxidase-conjugated rabbit antisheep IgG (1:2000 in 1\% BSA/PBS, Cabiochem-Novabiochem Corp) was added for $1.5 \mathrm{hrs}$ at $37^{\circ} \mathrm{C}$. After a further 6 washes with $0.5 \%$ Tween-20/PBS, $100 \mu \mathrm{L} /$ well of TMB substrate was added to each well. The color reaction was stopped 20 to 30 minutes later by addition of $100 \mu \mathrm{L} /$ well $2 \mathrm{~mol} / \mathrm{L} \mathrm{H}_{2} \mathrm{SO}_{4}$. ODs were read at $450 \mathrm{~nm}$, with a reference wavelength of $620 \mathrm{~nm}$. Levels of OVA-specific IgE in serum samples were expressed in arbitrary units (AUs), where 1 AU equals the OD of the 1:50 dilution of the pos- itive control sera. Serum OVA-specific IgE levels were then interpolated from the linear part of the OD versus AU standard curve of the positive control sera.

\section{Measurement of nitrite and nitrate production}

Nitrite production was quantified colorimetrically after the Griess reaction as described by Greenberg et al [19]. BAL fluid supernatant, or standard $(100 \mu \mathrm{L})$, was reacted with an equal volume of Griess reagent (1\% sulfanilamide $/ 0.1 \%$ naphthylethyllenedihydrochloride $/ 2.5 \%$ phosphoric acid, Sigma Chemical Co.) in duplicate microtiter wells at room temperature. Chromophore absorbance at $540 \mathrm{~nm}$ was determined. Nitrite concentration was calculated using sodium nitrite (BDH Chemical Co.) as a standard. To assay sample nitrate, $200 \mu \mathrm{L}$ BAL fluid supernatant, or standard containing $100 \mu \mathrm{L}$ of 200 $\mathrm{mM}$ ammonium formate (including $100 \mathrm{mM}$ HEPES, Sigma Chemical Co.) was reduced to nitrite at $37^{\circ} \mathrm{C}$ for 1 hr by adding $100 \mu \mathrm{L}$ nitrate reductase [E. coli (ATCC25922), American Type Collection, Rockville, $\mathrm{MD}$ ], followed by centrifugation to precipitate nonreacting E. coli for $5 \mathrm{~min}$, after which the nitrite was quantified as described above.

\section{Western blot analysis}

The lung was rapidly isolated following saline, ozone exposure for $3 \mathrm{~h}$, and ozone and OVA challenge was rapidly frozen. The lung tissues were homogenized at 3000 $\mathrm{rpm}$ in a solution containing $250 \mathrm{mmol} / \mathrm{L}$ sucrose, 1 $\mathrm{mmol} / \mathrm{L}$ ethylenediaminetetra-acetic acid, $0.1 \mathrm{mmol} / \mathrm{L}$ phenylmethylsulfonyl fluoride, and $10 \mathrm{mmol} / \mathrm{L}$ Tris- $\mathrm{HCl}$ buffer, at $\mathrm{pH}$ 7.6. Large tissue debris and nuclear fragments were removed by two low-speed spins in succession $(1000 \times \mathrm{g}$ for $10 \mathrm{~min}$ and $10,000 \times \mathrm{g}$ for $10 \mathrm{~min})$. Protein samples $(100 \mu \mathrm{g})$ were loaded and electrophoretically size-separated with a continuous system consisting of a $12.5 \%$ polyacrylamide resolving gel and $5 \%$ polyacrylamide stacking gel. The proteins were then electrophoretically transferred to a nitrocelluose membrane at $20 \mathrm{~V}$ overnight. The membranes were washed in Tris-based saline buffer (pH 7.4) containing 0.1\% Tween-20 (TBST), blocked with 5\% nonfat milk in TBST for 1 hour, and incubated with a 1:750 dilution of antirabbit polyclonal bNOS, eNOS, iNOS antibody (Transduction Laboratories, Lexington, KY, USA) in 2\% nonfat milk/TBST for $1 \mathrm{~h}$ at room temperature. The membranes were then incubated with a horseradish peroxidase-labeled goat antirabbit IgG (1:1200) in $2 \%$ nonfat milk in TBST for 2 hours. The bound antibody was detected by enhanced chemiluminescence (Amersham, Little Chalfont, Buckinghamshire, UK) on hyperfilm. The relative protein levels were determined by analyzing the signals of autoradiograms using the transmitter scanning videodensitometer. 


\section{Statistical analysis}

All data were analyzed using the SPSS version 7.5 for Windows. Data are expressed as mean \pm SEM. Inter-group comparisons were assessed by non-parametric method using Mann-Whitney U test. A p-value of less than 5\% was regarded as statistically significant.

\section{Results \\ Methacholine induced AHR and OVA specific IgE}

The OVA-sensitized/ozone-exposed/OVA-challenged group had significantly higher methacholine-induced $\mathrm{P}_{\mathrm{enh}}$ than the OVA-sensitized/saline challenged group (Ozone vs. OVA + Ozone; $P_{\text {enh }} 0: 0.79 \pm 0.02$ vs. $0.86 \pm 0.04, P_{\text {enh }}$ 3.12: $1.14 \pm 0.10$ vs. $1.23 \pm 0.02, P_{\text {enh }} 6.25: 1.23 \pm 0.12$ vs. $1.53 \pm 0.10, P_{\text {enh }} 12.5: 1.71 \pm 0.27$ vs. $1.88 \pm 0.16, P_{\text {enh }} 25:$ $1.97 \pm 0.34$ vs. $2.10 \pm 0.14, P_{\text {enh }} 50: 2.26 \pm 0.40$ vs. $2.59 \pm$ $0.14, P<0.01)$. The serum OVA-specific IgE levels were higher in the OVA-sensitized/ozone-exposed/OVA-challenged group compared with the OVA-sensitized/ozoneexposed/saline-challenged group and OVA-sensitized/ ozone-exposed/ozone-exposed group (Ozone vs. OVA + Ozone; $0.1 \pm 0.02$ AU vs. $0.35 \pm 0.09$ AU, $P<0.05)$.

\section{BAL differentials and lung histology}

The proportion of eosinophils in BAL fluids was significantly higher in the OVA-sensitized/ozone-exposed/OVAchallenged group than in the OVA-sensitized/saline-challenged and OVA-sensitized/ozone-exposed groups (8.2 \pm $1.21 \%$ vs. $1.4 \pm 0.28 \%$ vs. $1.2 \pm 0.03 \%$, respectively; $P<$ $0.05)$. The proportion of neutrophils in BAL fluid was significantly higher in the OVA-sensitized/ozone-exposed/ OVA-challenged group than in the other groups $(5.6 \pm$ $2.0 \%$ vs. $2.4 \pm 1.32 \%$ vs. $7.8 \pm 1.34 \% ; P<0.05)$. The development of inflammation in the lungs of OVA-sensitized/ ozone-exposed/OVA-challenged mice was assessed using a histologic examination of hematoxylin and eosinstained sections of lung tissue. Lungs were isolated on day 25 from mice sensitized with OVA and challenged with ozone or saline solution. Representative $5-\mu \mathrm{m}$ paraffin sections of lung tissue (three sections per $100 \mu \mathrm{m}$ ) were examined. Marked bronchial wall edema and neutrophils were observed in lung tissue sections from the OVA-sensitized/ozone-exposed/OVA-challenged group with eosinophil influx into the peribronchial, perivascular, and alveolar tissues. No inflammation was observed in lungs from OVA-sensitized/saline-challenged mice.

\section{Nitrite/nitrate concentrations and NOS isoforms expression}

The nitrate concentration in BAL fluids, which indicates the in vivo generation of NO in the airways, from the OVAsensitized/ozone-exposed/OVA-challenged group, was significantly greater than that of the OVA-sensitized/ saline-challenged group $(653.2 \pm 230.1$ vs. $212.5 \pm 27.8$ $\mu \mathrm{mol} / \mathrm{L}, P<0.05$, Fig. 1). Although the OVA-sensitized/
ozone-exposed/OVA-challenged group had significantly higher nNOS and eNOS levels than the OVA-sensitized/ saline-challenged group, it had significantly lower iNOS levels (Fig. 2).

\section{Discussion}

The important finding of this study was the down-regulation of pulmonary iNOS and the up-regulation of eNOS and nNOS in mice after ozone exposure. None of these enzymes was further affected by allergen exposure. We also found that the methacholine-induced $\mathrm{P}_{\mathrm{enh}^{\prime}}$ serum OVA-specific IgE levels, and eosinophils in BAL fluids were higher in the allergen-sensitized/ozone-exposed/ allergen-challenged group than in the allergen-sensitized/ saline-challenged group.

NOS is an enzyme that is active in airway epithelial cells, macrophages, neutrophils, mast cells, autonomic neurons, smooth muscle cells, fibroblasts, and endothelial cells. The chemical products of NOS in the lung vary with disease state and are involved in pulmonary neurotransmission, host defense, and airway and vascular smooth muscle relaxation [20].

Excessive production of NO following in vivo exposure of rats to ozone may be directly cytotoxic to lung cells and tissue [21]. Ozone inhalation induces iNOS expression in vivo, providing molecular evidence for the possible involvement of NO generation in ozone-induced pulmonary inflammation or lung damage [22]. Chiba et al. [23] reported that NOS activity in airway tissues was elevated in antigen-induced AHR rats, mainly due to the induction of iNOS in the airways. Constitutive eNOS and nNOS are not down-regulated in this animal model of AHR. In our study, although the levels of NO metabolites, eNOS, and nNOS increased in mice after ozone exposure, the expression of iNOS decreased, suggesting that eNOS and nNOS contribute to the formation of $\mathrm{NO}$ metabolites in mice after ozone exposure.

In this study, we found that eNOS and nNOS expression was up-regulated in the OVA-sensitized/ozone-exposed/ OVA-challenged group, which had greater AHR than that the OVA-sensitized/saline-challenged group, suggesting that eNOS and nNOS contribute to AHR. As previously described [23-25], iNOS is involved in inflammatory disease of the airways. If ozone induces pulmonary inflammation and NO plays a critical role in the ozone-induced pulmonary inflammation, it seems likely that iNOS plays a more important role in the generation of $\mathrm{NO}$ in mice after ozone exposure than eNOS and nNOS. Our results show that iNOS expression decreased in response to ozone exposure, while expression of eNOS and nNOS increased remarkably. The discrepancy between previous results [23-25] and this study might be due to the different 


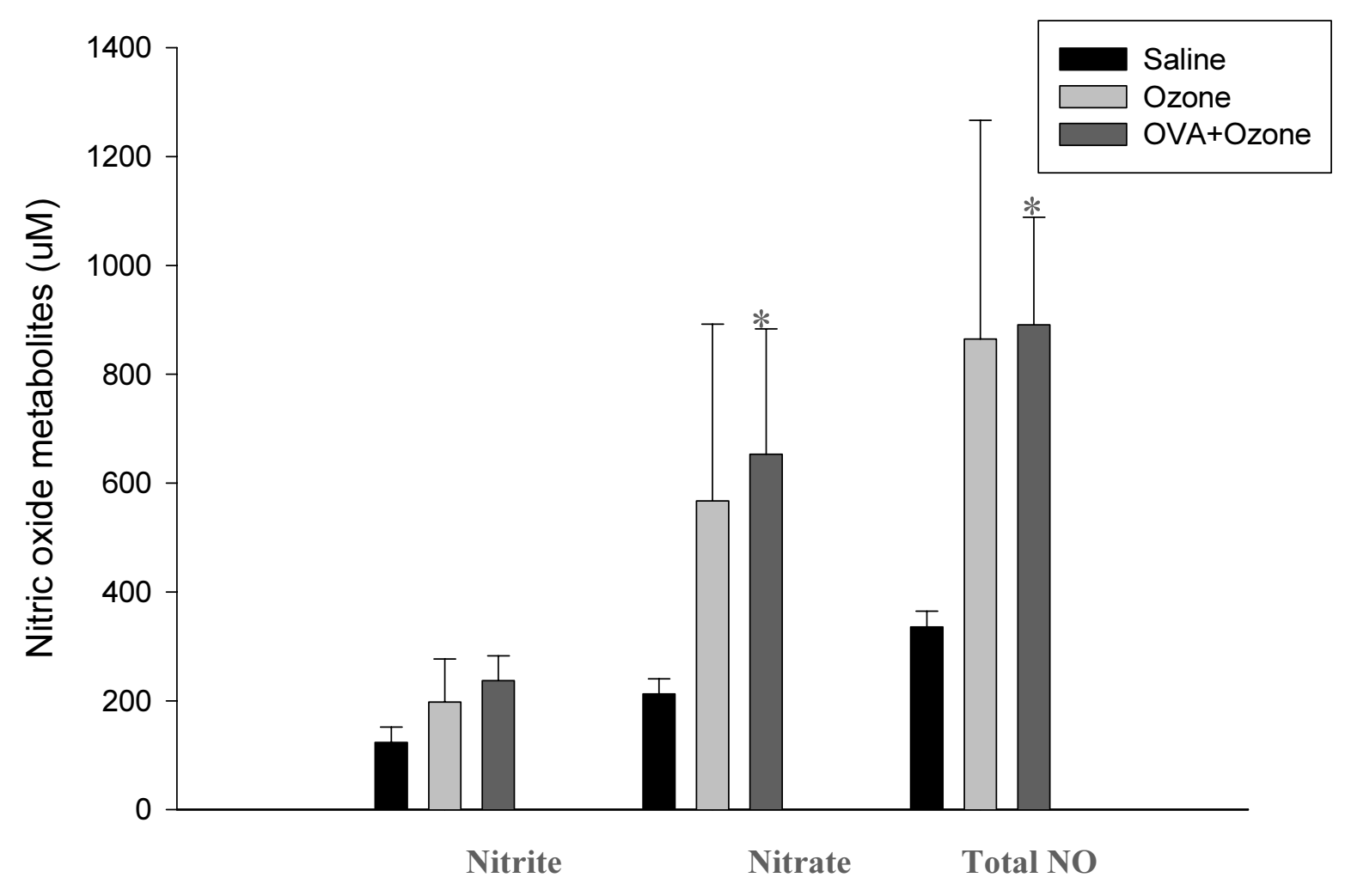

Figure I

The level of nitric oxide metabolites in bronchoalveolar lavage fluid. The level of nitric oxide metabolites in bronchoalveolar lavage fluid was increased in OVA sensitized-ozone exposed and OVA challenged group compared with OVA sensitized-saline challenged group. * $\mathrm{p}<0.05$ compared with OVA sensitized-saline challenged group.

exposure protocols (concentration and duration of exposure), species, and detection methods (mRNA and protein level) used. Moreover, the down-regulation of lung iNOS expression and the up-regulation of eNOS and nNOS in mice after ozone exposure were observed, and none of these enzymes were further affected by allergen exposure, suggesting that allergen exposure after ozone exposure did not affect NOS expression. Recently, Kobayashi et al. [26] reported that iNOS induction serves as a protective mechanism to minimize the effects of acute exposure to hyperoxia. In accordance with their study, we suggest that iNOS is involved in the anti-inflammatory effect that follows ozone exposure. Moreover, Fagan et al. [27] reported changes in the expression of eNOS and iNOS in the lungs of mice with severe hypoxia-induced pulmonary hypertension, using quantitative reverse transcription polymerase chain reaction: the level of lung eNOS was increased, while iNOS was below the limit of detection. Therefore, we suggest that NOS expression differs with the level of protein and RNA.

NO has been implicated as an important mediator of allergic inflammation via the selective inhibition of helper T lymphocytes (Th1), which secrete interferon (IFN)- $\gamma$ and in turn suppress the proliferation of Th2 lymphocytes [28]. Eosinophilic inflammation in asthma is driven by Th2 lymphocytes, which secrete interleukin (IL)-5. In this study, we found that the nitrate concentration and the 


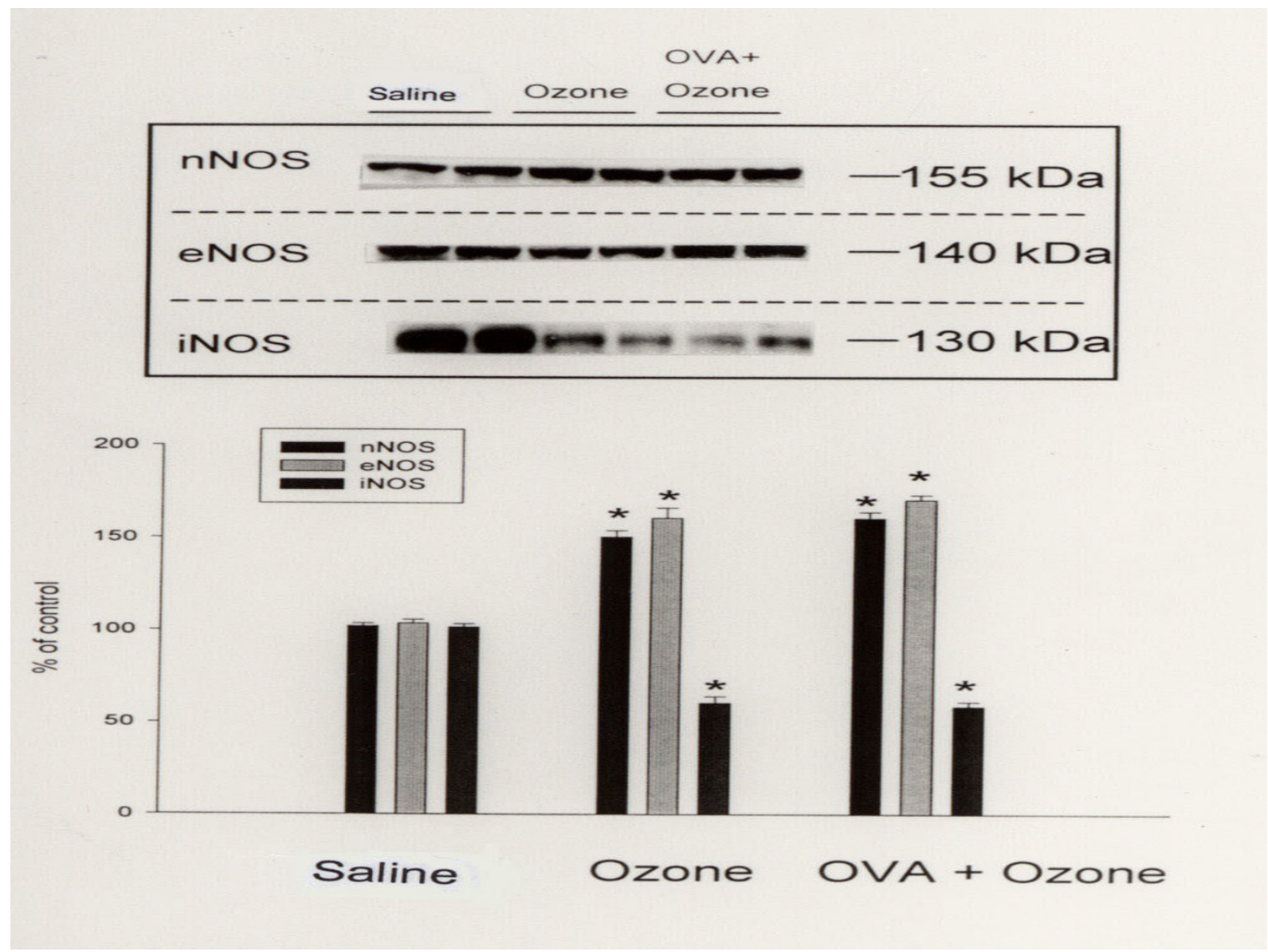

\section{Figure 2}

Western blot analysis of the expression of nNOS, eNOS, and iNOS in the lung tissue. Mice were categorized with OVA sensitized-saline challenged group (lane I and 2), OVA sensitized-ozone exposed group (lanes 3 and 4), and OVA sensitized-ozone exposed and OVA challenged group (lanes 5 and 6). Lung tissues were lysed and the extracts immunoblotted with antibody directed against nNOS, eNOS, and iNOS using a horseradish peroxidase-labeled goat antirabbit IgG $(I: I, 200)$ and enhanced chemiluminescence detection system. Each column represents the densitometric analysis. $* p<0.0$ I compared with OVA sensitized-saline challenged group.

proportion of neutrophils and eosinophils in BAL fluid were increased in the OVA-sensitized/ozone-exposed/ OVA-challenged group, suggesting that eNOS and nNOS expression after ozone exposure may be activated via neutrophilic and eosinophilic airway inflammation.

In summary, these findings suggest that the eNOS and nNOS isoforms induce airway responsiveness after ozone exposure, while iNOS is decreased. None of these enzymes were further affected by allergen exposure, suggesting that NOS is differentially involved in mice following ozone exposure.

\section{Acknowledgement}

This work was supported by grant R0I-2000-000-00 I55-0 From the Basic Research Program of the Korea Science \& Engineering Foundation

\section{References}

I. Arm JP, Lee TH: The pathobiology of bronchial asthma. Adv Immunol 1992, 5 I:323-382.

2. Moncada S, Palmer RMJ, Higgs EA: Biosynthesis of nitric oxide from $L$-arginine. A pathway for the regulation of cell function and communication. Biochem Pharmacol 1989, I I:I709-1715. 
3. Moncada S, Palmer RMJ, Higgs EA: Nitric oxide: physiology, pathophysiology and pharmacology. Pharmacol Rev I99I, 143: $109-142$.

4. Jang AS, Choi IS, Lee S, Seo JP, Yang SW, Park KO, Lee KY, Lee JU, Park CS, Park HS: Nitric oxide metabolites in induced sputum: a marker of airway inflammation in asthmatic subjects. Clin Exp Allergy 1999, 29: I I36-I I 42

5. Jang AS, Choi IS: Nitric oxide metabolites in patients with asthma: Induced sputum versus blood. Resp Med 1999, 93:912-918.

6. Committee of the Environmental and Occupational Health Assembly of the American Thoracic Society: Health effects of outdoor air pollution. Am J Respir Crit Care Med 1996, 1 53:3-50.

7. Holtzman MJ, Fabbri LM, O'Byrne PM, Gold BD, Aizawa H, Walters $\mathrm{EH}$, Alpert SE, Nadel JA: Importance of airway inflammation for hyperresponsiveness induced by ozone in dogs. Am Rev Respir Dis 1983, I 27:686-690.

8. Murlas CG, Roum JH: Sequence of pathologic changes in the airway mucosa of guinea pigs during ozone-induced bronchial hyperreactivity. Am Rev Respir Dis 1985, I 3 I:3 |4-320.

9. Basha MA, Gross KB, Gwizdala CJ, Haidar AH, Popovich J: Bronchoalveolar lavage neutrophilia in asthmatic and healthy volunteers after controlled exposure to ozone and filtered purified air. Chest 1994, 106: 1757-1765.

10. Seltzer J, Bigby BG, Stulbarg M, Holtzman MJ, Nadel JA, Ueki IF, Leikauf GD, Goetzl EJ, Boushey HA: O3-induced change in bronchial reactivity to methacholine and airway inflammation in humans. J Appl Physiol 1986, 60: I32I-I326.

II. Koren HS, Devlin RB, Graham DE, Mann R, McGee MP, Horstman DH, Kozumbo WJ, Becker S, House DE, McDonnell WF: Ozoneinduced inflammation in the lower airways of human subjects. Am Rev Respir Dis 1989, 139:407-4I5.

12. Jang AS, Choi IS, Lee JU: Neuronal nitric oxide synthase is associated with airway obstruction in BALB/c mice exposed to ozone. Respiration 2003, 70:95-9.

13. Brusselle GG, Kips JC, Tavernier JH, van der Heyden JG, Cuvelier CA, Pauwels RA, Bluethmann $\mathrm{H}$ : Attenuation of allergic airway inflammation in IL-4 deficient mice. Clin Exp Allergy 1994, 24:73-80.

14. Jang AS, Choi IS, Kim SW, Song BC, Yeum CH, Jung JY: Airway obstruction after acute ozone exposure in BALB/c mice using barometric plethysmography. Kor J Intern Med 2003, 18:1-5.

15. Hamelmann E, Schwarze J, Takeda K, Oshiba A, Larsen GL, Irvin CG, Gelfand EW: Noninvasive measurement of airway responsiveness in allergic mice using barometric plethysmography. Am J Respir Crit Care Med 1997, 156:766-775.

16. Johanson WG Jr, Pierce AK: A noninvasive technique for measurement of airway conductance in small animals. J Appl Physiol 1971, 30:146-150.

17. Pennock BE, Cox CP, Rogers RM, Cain WA, Wells JH: A noninvasive technique for measurement of changes in specific airway resistance. J Appl Physiol I 979, 46:399-406.

18. Brusselle GG, Kips JC, Tavernier JH, Van der Heyden JG, Cuvelier CA, Pauwels RA, Bluethmann H: Attenuation of allergic airway inflammation in IL-4 deficient mice. Clin Exp Allergy 1994, 24:73-80.

19. Greenberg SS, Xie J, Spitzer JJ, Wang J, Lancaster J, Grishham MB, Powers DR, Giles TD: Nitro containing L-arginine analogs interfere with assays for nitrate and nitrite. Life Sciences 1995, 57:1949-196|.

20. Gaston B, Drazen JM, Loscalzo J, Stamier JS: The biology of nitrogen oxides in the airways. Am J Respir Crit Care Med 1994, |49:538-55|.

21. Barnes PJ: Nitric oxide and airways. Eur Respir J 1993, 6: 163-165.

22. Haddad EB, Liu SF, Salmon M, Robichaud A, Barnes PJ, Chung KF: Expression of inducible nitric oxide synthase mRNA in Brown Norway rats exposed to ozone: effect of dexamethasone. Eur J Pharmacol 1995, 293:287-290.

23. Chiba Y, Arimoto T, Yoshikawa T, Misawa M: Elevated nitric oxide synthase activity concurrent with antigen-induced airway hyperresponsiveness in rats. Exp Lung Res 2000, 26:535-549.

24. Liu SF, Haddad EB, Adcock I, Salmon M, Koto H, Gilbey T, Barnes PJ, Chung KF: Inducible nitric oxide synthase after sensitization and allergen challenge of Brown Norway rat lung. $\mathrm{Br} J$ Pharmacol 1997, | 2 I:124|-1246.
25. Haddad EB, Liu SF, Salmon M, Robichaud A, Barnes PJ, Chung KF: Expression of inducible nitric oxide synthase mRNA in Brown Norway rats exposed to ozone: effect of dexamethasone. Eur J Pharmacol 1995, 293:287-290.

26. Kobayashi $H$, Hataishi R, Mitsufuji $H$, Tanaka M, Jacobson M, Tomita T, Zapol WM, Jones RC: Antiinflammatory properties of inducible nitric oxide synthase in acute hyperoxic lung injury. $A m J$ Respir Cell Mol Biol 200I, 24:390-397.

27. Fagan KA, Morrissey B, Fouty BW, Sato K, Harral JW, Morris KG Jr, Hoedt-Miller M, Vidmar S, McMurtry IF, Rodman DM: Upregulation of nitric oxide synthase in mice with severe hypoxia-induced pulmonary hypertension. Respir Res 200I, 2:306-3I3.

28. Barnes PJ: Nitric oxide and airway disease. Ann Med 1995, 27:389-393
Publish with Bio Med Central and every scientist can read your work free of charge

"BioMed Central will be the most significant development for disseminating the results of biomedical research in our lifetime. "

Sir Paul Nurse, Cancer Research UK

Your research papers will be:

- available free of charge to the entire biomedical community

- peer reviewed and published immediately upon acceptance

- cited in PubMed and archived on PubMed Central

- yours - you keep the copyright

Submit your manuscript here:

http://www.biomedcentral.com/info/publishing_adv.asp
BioMedcentral 